\title{
Pd-Catalyzed Allylic Alkylation of Ketones
}

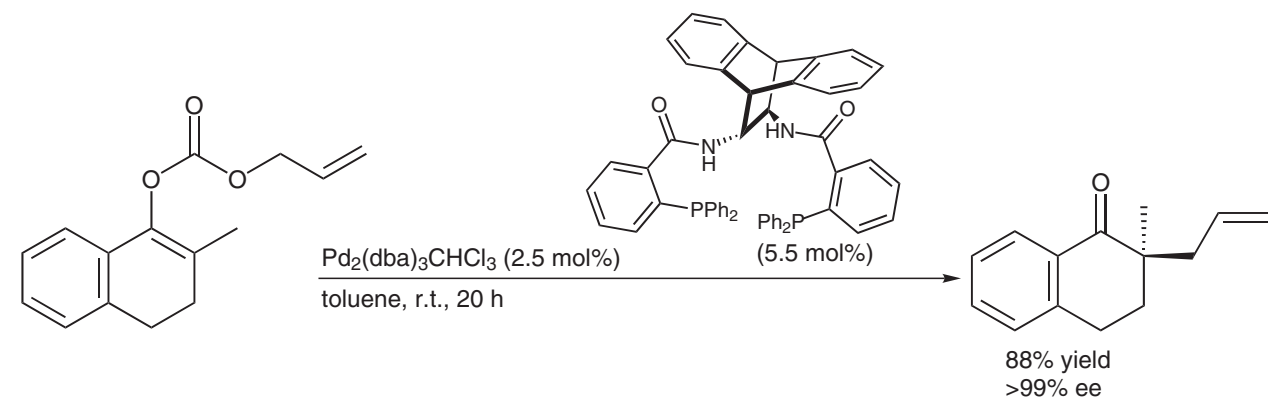

Significance: The synthesis of $\alpha$-chiral quaternary cyclohexanones has remained a challenge in organic synthesis. This report shows excellent yields with ee's over $90 \%$ for many substrates and thus is an important step for total syntheses.
Comment: Asymmetric allylation of reactive ketone enolates is a challenging issue of organic synthesis. This paper reports a method to create both tertiary and quaternary stereoecenters $\alpha$ - to ketones, and mark an important advance in this area.

Similar results were reported last year: D. Behenna, B. M. Stoltz J. Am. Chem. Soc. 2004, 126, 15044-15055.
Metal-Catalyzed

Asymmetric

Synthesis and Stereoselective Reactions

Key Words

allylic alkylation allyl enol carbonate palladium 